J. Lake Sci. (湖泊科学), 2019, 31(2): 416-428

DOI 10. 18307/2019. 0211

(c) 2019 by Journal of Lake Sciences

\title{
旅游酒店排污影响下的岩溶地下水水化学变化
}

\author{
杨平恒 ${ }^{1}$, 詹兆君 ${ }^{1}$, 明晓星 ${ }^{1}$, 陈 峰 ${ }^{1}$, 任 娟 $^{1}$, 邓书金 ${ }^{2}$, 洪爱花 ${ }^{2}$
}

(1: 西南大学地理科学学院,岩溶环境重庆市重点实验室,自然资源部岩溶生态环境一重庆南川野外基地, 重庆 400715)

(2: 重庆地质矿产勘查开发局南江水文地质工程地质队, 重庆市地下水资源利用与环境保护实验室, 重庆 401121)

摘 要: 岩溶地下水系统具有高度的开放性和脆弱性, 使得地下水极易遭受污染. 为探究旅游酒店排污对岩溶地下水水 化学变化的影响, 以金佛山世界自然遗产地水房泉流域为例,对水房泉地下水的水化学进行自动化监测,对流域内雨水、 土壤水、某酒店自来水、污废水进行定期采集,结合流域硝酸盐氮氧同位素分析. 结果表明,监测期间水房泉水化学变化 随酒店人住游客量总体表现为 3 个阶段: 前期受降雨影响显著, 旅游高峰期间水质急剧恶化, 后期水质明显好转. 酒店生 活污废水的排放成为水房泉水化学演变的重要因素, 硝酸盐氮氧同位素表明水房泉的 $\mathrm{NO}_{3}^{-}$主要来自粪便、污废水以及土 壤 $\mathrm{N}$ 的混合. $\mathrm{H}_{2} \mathrm{SO}_{4}$ 及污水中 $\mathrm{HCl}$ 、有机酸等可能参与了碳酸盐岩的溶蚀, 使水房泉 $\mathrm{Ca}^{2+} 、 \mathrm{Mg}^{2+} 、 \mathrm{HCO}_{3}^{-}$浓度增加明显. 流域 岩溶管道发育, 地下水流速快, 使污染物质扩散迅速,故在研究期间水房泉主要离子的浓度高峰对污废水排放高峰的响 应仅滞后约 $4 \mathrm{~d}$.

关键词: 酒店排污;岩溶地下水;水化学特征;氮氧同位素;金佛山;水房泉

\section{Hydrochemical variation of the karst groundwater impacted by the contaminant discharge from a tourism hotel}

YANG Pingheng ${ }^{1}$, ZHAN Zhaojun ${ }^{1}$, MING Xiaoxing ${ }^{1}$, CHEN Feng ${ }^{1}$, REN Juan ${ }^{1}$, DENG Shujin ${ }^{2}$ \& HONG Aihua ${ }^{2}$

(1: School of Geographical Sciences, Southwest University, Chongqing Key Laboratory of Karst Environment, Field Scientific Observation \& Research Base of Karst Eco-environments at Nanchuan in Chongqing, Ministry of Natural Resources of the People's Republic of China, Chongqing 400715, P.R.China)

(2: Laboratory of Chongqing Groundwater Resource Utilization and Environmental Protection, Nanjiang Hydrogeological Team Under the Chongqing Geological Bureau of Geology and Minerals Exploration, Chongqing 401121, P.R. China)

\begin{abstract}
Karst groundwater system is characterized by properties of openness and vulnerability, which makes the groundwater vulnerable to pollution. To investigate the hydrochemical variation of the karst groundwater impacted by a tourism hotel, Shuifang Spring at the core region of Jinfoshan Karst World Heritage Site, was selected to be the studied site. Hydrochemical data of Shuifang Spring were automatically monitored. The precipitation, soil water, tap water, and wastewater from hotel in the basin were manually sampled each month. Dual stable isotopes of nitrogen and oxygen were also employed. Results shows that Shuifang Spring exhibited three hydrochemical stages along with the tourism accommodation amount during the monitoring period. At the early stage of tourism peak, the hydrochemical characteristics of Shuifang Spring was significantly influenced by the rainfall. During the tourism peak, the water quality was sharply deteriorated. After the boom of tourists, the water quality was obviously improved. Discharge from the hotel domestic wastewater therefore became an important factor in the geochemical evolution of Shuifang Spring. Result of the dual stable isotopes of nitrogen and oxygen shows that nitrate of Shuifang Spring was primarily derived from manure and sewage, in addition to soil organic N. Acid, such as $\mathrm{H}_{2} \mathrm{SO}_{4}, \mathrm{HCl}$ and organic acids from sewage, probably involved in erosion of carbonate rock, which resulted in elevated concentrations of $\mathrm{Ca}^{2+}, \mathrm{Mg}^{2+}$ and $\mathrm{HCO}_{3}^{-}$in Shuifang Spring. The peak concentration of major elements in
\end{abstract}

* 国家自然科学基金项目 (41103068) 和中央高校基本科研业务费专项 (XDJK2018AB002) 联合资助. 2018-06-25 收 稿;2018-08-05 收修改稿. 杨平恒(1983 ), 男,博士, 副教授; E-mail: balance@ swu.edu.cn; pinghengyang@ 126. com. 
Shuifang Spring was four-day delay relative to the peak of tourism accommodation as a result of rapid diffusion of pollutants in the well-developed karst conduit and highly flow velocity.

Keywords: Hotel sewage; karst groundwater; hydrochemical characteristics; nitrogen and oxygen isotopes; Jinfoshan; Shuifang Spring

受岩溶区特殊地质环境条件的影响, 岩溶地下水系统具有高度的开放性和脆弱性, 对外界环境变化极 为敏感,因此含水层类型、水岩作用、人类活动等都可能对岩溶地下水系统产生深刻的影响 ${ }^{[1-6]}$, 目前关于农

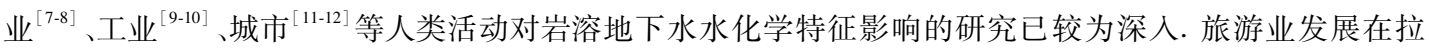
动地方经济增长的同时, 也带来了地表水体污染 ${ }^{[13-14]}$ 、固体废弃物污染 ${ }^{[15]}$ 、土壤污染 ${ }^{[16]}$ 、景区钻华景观退 化 ${ }^{[17]}$ 等环境和生态问题. 岩溶环境是西南地区重要的自然旅游资源载体, 旅游酒店污染物的排放可能对脆 弱而敏感的岩溶地下水系统造成严重影响. 在旅游酒店排污的影响下, 岩溶地下水主要表现为短时间尺度 内的水质恶化 ${ }^{[18-19]}$,而对其水化学变化过程、机理的认识还有待深人研究.

本文选取重庆市金佛山世界自然遗产地为研究对象, 开展自动化监测和采样, 获取研究区内水房泉 2016 年 7-9 月的水化学信息,结合流域内与其联系密切的雨水、土壤水、某酒店自来水、污废水水化学特 征, 结合硝酸盐氮氧同位素, 分析酒店排污影响下地下水的水化学特征、影响因素、变化过程及其原因, 以期 为岩溶地下水的保护、利用及金佛山旅游活动的科学管理提供依据.

\section{1 研究区概况}

金佛山 $\left(28^{\circ} 55^{\prime} \sim 29^{\circ} 07^{\prime} \mathrm{N}, 107^{\circ} 06^{\prime} \sim 107^{\circ} 18^{\prime} \mathrm{E}\right)$ 位于四川盆地东南部的渝黔交接带, 处于重庆市南川区南 部, 主峰风吹岭海拔 $2251 \mathrm{~m}$, 总面积约 $1300 \mathrm{~km}^{2}$. 金佛山是一个宽缓的向斜构造, 轴部发育二叠系碳酸盐岩 地层, 在山顶海拔约 $2100 \mathrm{~m}$ 形成了面积较大的缓坡台地, 洼地、落水洞、洞穴等岩溶形态丰富 (图 1). 水房泉 位于金佛山西坡的断崖上, 海拔约 $2050 \mathrm{~m}$. 水房泉流量为 $0.5 \sim 38 \mathrm{~L} / \mathrm{s}$, 平均流量为 $6.5 \mathrm{~L} / \mathrm{s}$, 大气降水是其主 要补给来源 ${ }^{[20]}$.

金佛山的垂直气候分带明显, 山体下部为亚热带季风性湿润气候, 多年平均气温、降水量分别为 $16.6^{\circ} \mathrm{C}$ 、 $1286.5 \mathrm{~mm}$; 山体上部具有温带湿润气候的特征, 多年平均气温、降水量分别为 $8.2^{\circ} \mathrm{C} 、 1434.5 \mathrm{~mm}$, 降水集中分 布于 $4-10$ 月,约占全年降水量的 $83 \%{ }^{[21]}$. 从山下向山顶依次发育黄壤、暗黄壤、黄棕壤和草甸土.

金佛山于 2013 年被评为国家 5A 级景区, 2014 年被列人 “世界自然遗产名录”. 近年来景区游客接待量 保持大幅增长,已从 2010 年的 27.45 万人次增长至 2014 年的 77.85 万人次 ${ }^{[22]}$. 夏季是金佛山游客的避暑高 峰时段, 冬季因山顶的降雪和雾淞景观也形成旅游旺季. 水房泉流域内建有一大型酒店, 该酒店、㕌房所用 自来水主要从其东北部的仙女洞引出 (图 1), 为天然的岩溶地下水. 餐饮、住宿等产生的生活污废水通过药 池坝三级化粪池进行生化沉淀、降解处理, 再通过 $1^{\#}$ 落水洞, 灌人含水层 (图 2a). 通过多次示踪试验表明, 该酒店、 $1^{\#}$ 落水洞与水房泉之间存在明显的水力联系, 岩溶地下管道发育, 且规模较大, 地下水平均流速达 $16.6 \sim 18.4 \mathrm{~m} / \mathrm{h}$ ( 未发表). 水房泉是区域含水层的主要出口 (图 1、图 2a), 生活污废水在化粪池中的最短滞 留时间为 $16.9 \mathrm{~h}$, 经 $1^{\#}$ 落水洞到达水房泉最快仅需 $26.8 \mathrm{~h}$, 平均为 $90.3 \mathrm{~h}^{[19]}$ (图 $2 \mathrm{~b}$ ). 较短的污水处理时间和 有限的化粪池处理工艺很可能难以完全降解污水中的污染物, 加上岩溶管道含水介质发育, 使岩溶地下水 极易遭受污染.

\section{2 研究方法}

\section{1 野外自动监测}

利用 Manta2 多参数水质分析仪 (美国 Eureka 公司) 自动监测水房泉的水温、水位、 $\mathrm{pH}$ 值、电导率、溶解 氧、浊度、硝态氮 $\left(\mathrm{NO}_{3}^{-}-\mathrm{N}\right)$ 等指标, 测试精度分别为 $0.01^{\circ} \mathrm{C} 、 0.1 \mathrm{~cm} 、 0.01 、 0.01 \mu \mathrm{S} / \mathrm{cm} 、 0.01 \mathrm{mg} / \mathrm{L} 、 0.1 \mathrm{NTU} 、 0.1$ $\mathrm{mg} / \mathrm{L}$, 监测时间间隔为 $10 \mathrm{~min}$. 使用前对仪器进行校准. 泉口流量数据通过流量一水位关系曲线计算而得. 在风吹岭设置 HOBO 小型自动气象站 (美国 ONSET 公司) 自动记录气温、降水数据, 精度分别为 $0.01^{\circ} \mathrm{C}$ 、 $0.01 \mathrm{~mm}$, 记录时间间隔为 $10 \mathrm{~min}$. 


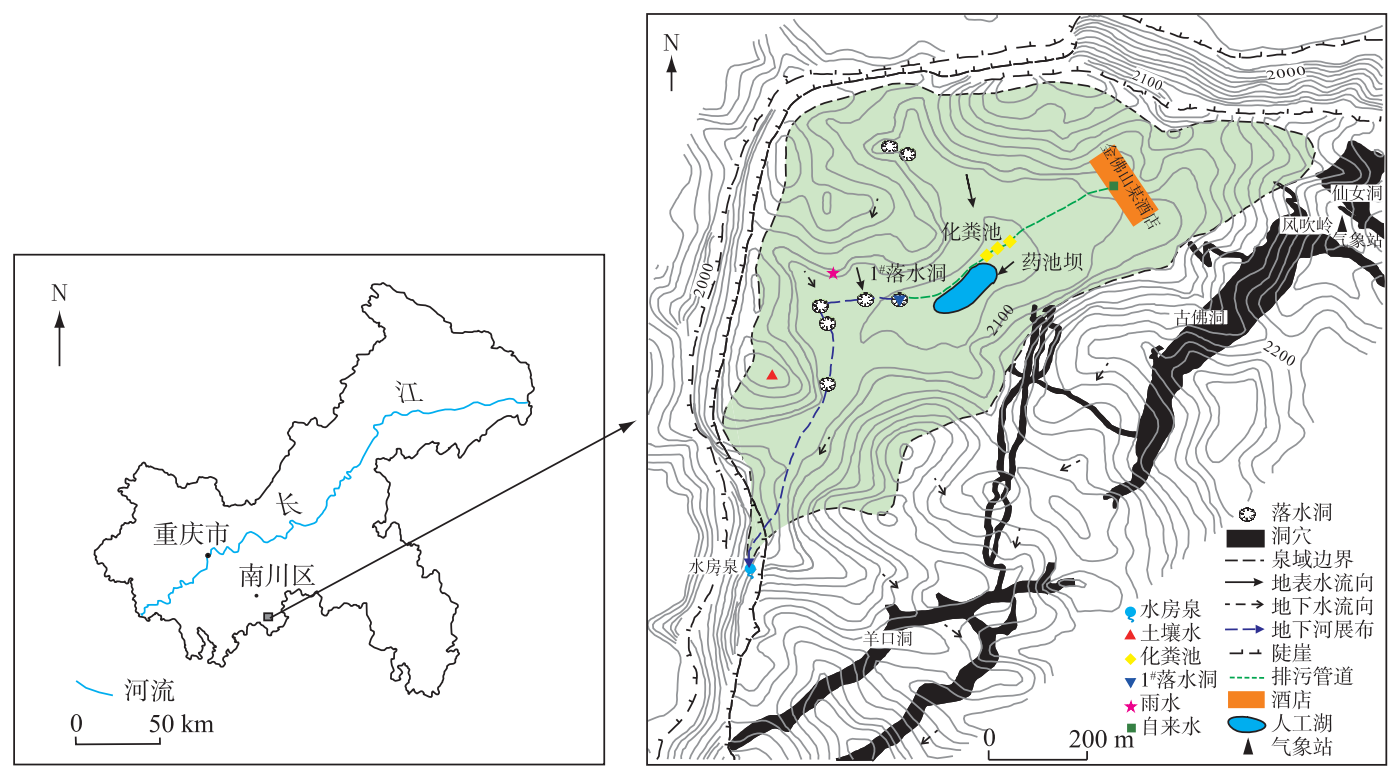

图 1 研究区位置及水文地质示意

Fig.1 Location and hydrogeology of the study area

(a)

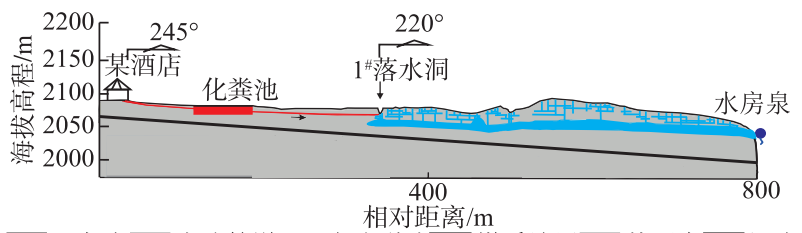

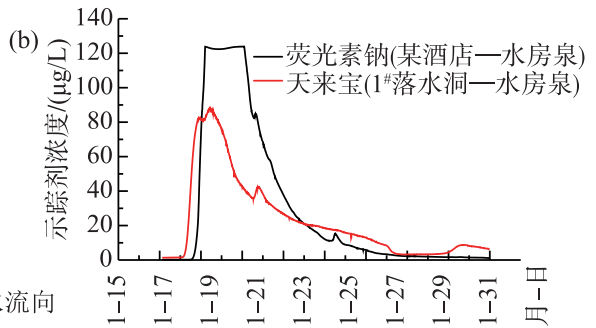

图 2 金佛山某酒店一水房泉垂直剖面 (a) 和示踪剂回收曲线 (b) (修改自文献 [19])

Fig. 2 Vertical profile from the hotel in Jinfoshan to Shuifang Spring (a), and breakthrough curves of tracers (b) (modified from reference [19])

\section{2 样品采集与测试}

在水房泉泉口安装 Sigma SD900 自动采样器 (美国 Hach 公司), 每天自动采集水样 1 L. 为防止水样蒸 发, 采样前在样品瓶中加人 $20 \mathrm{ml}$ 液体石蜡, 后将获取的水样带回实验室分装. 分别用洁净的高密度聚乙烯 瓶采集, 用于测试阴、阳离子,低温保存至检测. 对水房泉的监测时段为 2016 年 7 月 1 日-9 月 17 日,7 月 5 日-7月 8 日因自动采样器出现故障, 未采集到水样, 使部分样品缺失.

参照我国大气降水采集与保存标准( GB 13580.2- 1992), 在流域内安装雨水收集装置; 选取流域内一 较大洼地, 在距地表 $60 \mathrm{~cm}$ 深处安放渗流土壤水收集装置 ${ }^{[23]}$ (采样点位置见图 1). 分别于 2016 年 7 月 9 日、

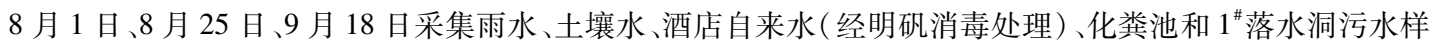
品, 使用 Multi3430 多参数水质分析仪 (德国 WTW 公司) 测定各水体的水温、电导率、pH 值, 其精度分别为 $0.1^{\circ} \mathrm{C} 、 1 \mu \mathrm{S} / \mathrm{cm} 、 0.001 \mathrm{pH}$ 单位. 采用 DR2800(美国 Hach 公司) 测定铵态氮 $\left(\mathrm{NH}_{4}^{+}-\mathrm{N}\right.$ ) 浓度, 精度为 $0.001 \mathrm{mg} / \mathrm{L}$. 使用碱度计 (德国 Merck 公司) 测试各水体 $\mathrm{HCO}_{3}^{-}$质量浓度,精度为 $0.1 \mathrm{mmol} / \mathrm{L}$.

为验证地下水硝酸盐的污染源,于 2017 年 4- 10 月对酒店自来水、 1 \#落水洞和水房泉进行硝酸盐 ${ }^{15} \mathrm{~N}_{\mathrm{NO}_{3}}$ 和 ${ }^{18} \mathrm{O}_{\mathrm{NO}_{3}}$ 定期采样, 样品现场经 $0.22 \mu \mathrm{m}$ 混合纤维素滤膜过滤后装人聚乙烯瓶中, 送回实验室冷冻保存至 
检测.

\section{3 实验室分析}

$\mathrm{K}^{+} 、 \mathrm{Na}^{+} 、 \mathrm{Ca}^{2+} 、 \mathrm{Mg}^{2+}$ 等阳离子浓度检测采用 ICP-OES Optima 2100DV (美国 PerkinElmer 公司) 完成, 仪器 $1 \mathrm{~h}$ 内相对标准偏差 $\leqslant 0.5 \%$. $\mathrm{NO}_{3}^{-} 、 \mathrm{SO}_{4}^{2-} 、 \mathrm{PO}_{4}^{3-}$ 离子浓度测定参照饮用天然矿泉水检测方法 ( $\mathrm{GB} / \mathrm{T} 8538-$ 2008 ), 使用紫外分光光度计(UV2450, 日本岛津公司) 进行, $\mathrm{Cl}^{-}$浓度测定采用 $\mathrm{AgNO}_{3}$ 滴定法. 以上测试均在 岩溶环境重庆市重点实验室完成. 方解石饱和指数 (SIc) 、总溶解固体 (TDS) 分别由 WATSPEC15、Aquachem V.5.1 软件计算得出. 金佛山某酒店游客住宿量数据经酒店相关部门不完全统计获取.

$\delta^{15} \mathrm{~N}_{\mathrm{NO}}$ 和 $\delta^{18} \mathrm{O}_{\mathrm{NO}}$ 检测利用特异性的反硝化细菌将 $\mathrm{NO}_{3}^{-}$转化为 $\mathrm{N}_{2} \mathrm{O}$, 再利用 ISOPRIME100-Tracegas 痕量 气体一同位素质谱联用仪 (英国 Isoprime 公司) 完成 $\mathrm{N}_{2} \mathrm{O}$ 的 $\mathrm{N} 、 \mathrm{O}$ 同位素测定, 采用 USGS32 $\left(\delta^{15} \mathrm{~N}=180 \%\right.$, $\left.\delta^{18} \mathrm{O}=25.7 \% 0\right) 、 \operatorname{USGS} 34\left(\delta^{15} \mathrm{~N}=-1.8 \% 0, \delta^{18} \mathrm{O}=-27.9 \% 0\right) 、 \operatorname{USGS} 35\left(\delta^{15} \mathrm{~N}=2.7 \% 0, \delta^{18} \mathrm{O}=57.5 \% 0\right)$ 为标准, 用两点 校正方程对所测定的气体进行校正, 检测精度为 $0.01 \%, \delta^{15} \mathrm{~N}_{\mathrm{NO}_{3}} 、 \delta^{18} \mathrm{O}_{\mathrm{No}}$ 的测定结果标准偏差分别 $<0.4 \%$ 、 $<0.22 \%$. 以上同位素测定工作在中国农业科学院农业环境稳定同位素实验室完成.

\section{3 结果与分析}

\section{1 雨水、土壤水、自来水、污水水化学特征}

雨水中的主要阴、阳离子为 $\mathrm{Cl}^{-} 、 \mathrm{SO}_{4}^{2-}$ 和 $\mathrm{Ca}^{2+}$ (表 1), 水化学类型呈 $\mathrm{Cl}_{-}-\mathrm{SO}_{4}-\mathrm{Na}-\mathrm{Ca}$ 型 (图 3). 平均 $\mathrm{pH}$ 值为 5.34 , 为流域内各采样点最低 (表 1 ), 属于硫酸型酸雨. 受雨水补给的土壤水, 其水化学类型相对复杂, 为 $\mathrm{HCO}_{3}-\mathrm{SO}_{4}-\mathrm{Na}-\mathrm{Ca} 、 \mathrm{HCO}_{3}-\mathrm{Cl}-\mathrm{Na}-\mathrm{Ca}$ 型 (图 3). 受到土壤中有机氮硝化作用的影响 ${ }^{[4]}$, 土壤水的 $\mathrm{NO}_{3}^{-}$离子浓度 最高值, 为 $40.2 \mathrm{mg} / \mathrm{L}$. 雨水、土壤水中 $\mathrm{Ca}^{2+} 、 \mathrm{Mg}^{2+} 、 \mathrm{SO}_{4}^{2-} 、 \mathrm{NO}_{3}^{-} 、 \mathrm{NH}_{4}^{+} 、 \mathrm{PO}_{4}^{3-}$ 等离子浓度变幅较大 (表 1 ).

自来水的水化学类型为 $\mathrm{HCO}_{3}-\mathrm{SO}_{4}$ - $\mathrm{Ca}$ 型 (图 3). 酒店从仙女洞引出的岩溶地下水水质良好, 因流经煤 系地层, 故可能受到黄铁矿的氧化作用 ${ }^{[24]}$, 加上自来水的日常消毒中使用了明矾 $\left(\mathrm{KAl}\left(\mathrm{SO}_{4}\right)_{2} \cdot 12 \mathrm{H}_{2} \mathrm{O}\right)$, 使 其 $\mathrm{SO}_{4}^{2-}$ 浓度最高达 $50.3 \mathrm{mg} / \mathrm{L}$ (表 1 ).

与自来水相比,化粪池污水中的 $\mathrm{K}^{+} 、 \mathrm{Na}^{+} 、 \mathrm{NH}_{4}^{+} 、 \mathrm{Cl}^{-} 、 \mathrm{PO}_{4}^{3-}$ 平均浓度虽大幅升高 $(\mathrm{CV}$ 值均 $>30 \%)$, 且 $\mathrm{NO}_{3}^{-}$ 浓度均值为各采样点最高 (表 1), 但是其水化学类型仍为 $\mathrm{HCO}_{3}$ - $\mathrm{Ca}$ 型 (图 3), 可见化粪池的三级生化降解 处理过程对污水有一定的净化作用.

$1^{\#}$ 落水洞污水的水化学类型为 $\mathrm{HCO}_{3}-\mathrm{Ca} 、 \mathrm{HCO}_{3}-\mathrm{Na}-\mathrm{Ca}$ 型 (图 3). 据调查, 旅游高峰期间某酒店污废水排 放量剧增, 因化粪池收纳量和降解能力有限, 部分污废水未经处理而直接排放至 $1^{\#}$ 落水洞, 再汇人地下水系 统. 因此, $1^{\#}$ 落水洞污水的电导率及 $\mathrm{NH}_{4}^{+}$等离子浓度较化粪池污水显著偏高, 并为各采样点最高 (表 1 ). 此 外,其变幅远高于化粪池污水 (表 1), 水化学类型也变化明显 (图 3). 而其 $\mathrm{NO}_{3}^{-}$浓度则为各采样点最低 (表 1 ), 这可能由于污水中的缺氧环境 (溶解氧均值 $2.71 \mathrm{mg} / \mathrm{L}$, 为各采样点最低) 抑制了 $\mathrm{NH}_{4}^{+}$硝化作用的进 行 ${ }^{[25]}$, 也可能与污水中有机质氧化作用对 $\mathrm{NO}_{3}^{-}$的消耗有关 ${ }^{[26]}$.

\section{2 旅游活动高峰期及其前、后水房泉水化学变化特征}

总体而言, 水房泉的水化学类型为 $\mathrm{HCO}_{3}$-Ca 型 (图 3). 与流域内其他水体相比, 其 $\mathrm{pH}$ 值、溶解氧整体高 于化粪池和 $\mathrm{I}^{\#}$ 落水洞污水 (表 $1 、 2$ ), 电导率及 $\mathrm{Ca}^{2+} 、 \mathrm{Mg}^{2+} 、 \mathrm{HCO}_{3}^{-} 、 \mathrm{~K}^{+} 、 \mathrm{Na}^{+} 、 \mathrm{Cl}^{-} 、 \mathrm{NH}_{4}^{+} 、 \mathrm{PO}_{4}^{3-}$ 浓度均值仅次于化

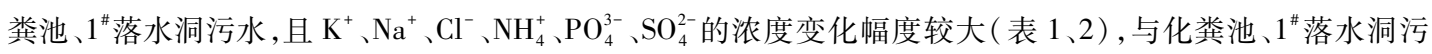
水的离子变化特征相似. 选取 2016 年 6 月代表研究区的非旅游高峰期, 由表 2 可知, 旅游高峰期间水房泉电 导率及主要离子浓度均值较非旅游高峰期均明显升高, 其中以 $\mathrm{K}^{+} 、 \mathrm{Na}^{+} 、 \mathrm{NH}_{4}^{+} 、 \mathrm{PO}_{4}^{3-}$ 最为明显, $\mathrm{NO}_{3}^{-}$浓度增幅 相对较小,溶解氧、 $\mathrm{pH}$ 值则有所下降.

在自动化监测期间,受研究区及周边降雨、气温变化的影响,山顶酒店游客住宿量的阶段变化明显, 且 大多在周末出现住宿高峰 (图 4). 水房泉作为整个流域的主要出口, 其水化学动态变化与游客住宿变化密 切相关,表现为以下 3 个阶段. 
表 1 水房泉流域各水体水化学特征值 ${ }^{*}$

Tab.1 Hydrochemical data of the sample sites in the basin of Shuifang Spring

\begin{tabular}{|c|c|c|c|c|c|c|c|c|c|c|c|c|c|c|c|}
\hline 采样点 & 气样时间 & $\mathrm{Ca}^{2+}$ & $\mathrm{Mg}^{2+}$ & $\mathrm{K}^{+}$ & $\mathrm{Na}^{+}$ & $\mathrm{HCO}_{3}^{-}$ & $\mathrm{Cl}^{-}$ & $\mathrm{SO}_{4}^{2-}$ & $\mathrm{NO}_{3}^{-}$ & $\mathrm{NH}_{4}^{+}$ & $\mathrm{PO}_{4}^{3-}$ & \multicolumn{4}{|c|}{ 水温 溶解氧 $\mathrm{pH}$ 值电导率 } \\
\hline \multirow[t]{6}{*}{ 雨水 } & $2016-07-09$ & 0.08 & MDL & 0.18 & 0.16 & 0 & 3.55 & 3.77 & 1.50 & 0.40 & 0.01 & 25.4 & 6.07 & 5.34 & 10.0 \\
\hline & $2016-08-01$ & 0.51 & MDL & 0.19 & 0.28 & 0 & 4.25 & 3.88 & 2.16 & 0.24 & 0.03 & 24.0 & 3.37 & 5.54 & 18.0 \\
\hline & $2016-08-25$ & 0.33 & 0.04 & 0.23 & 0.20 & 0 & 2.84 & 4.88 & 2.30 & 0.82 & 0.20 & 22.7 & 6.88 & 5.33 & 28.6 \\
\hline & $2016-09-18$ & 1.34 & 0.00 & 0.18 & 0.25 & 0 & 2.13 & 8.42 & 14.0 & 0.45 & 0.06 & 15.5 & 7.78 & 5.15 & 21.3 \\
\hline & 平均值 & 0.57 & 0.01 & 0.20 & 0.22 & 0 & 3.19 & 5.24 & 4.97 & 0.48 & 0.08 & 21.9 & 6.03 & 5.34 & 19.5 \\
\hline & $C V$ 值 & 83.3 & 168 & 11.5 & 20.6 & 0 & 24.8 & 36.0 & 104 & 44.4 & 94.7 & 17.4 & 27.3 & 2.59 & 34.3 \\
\hline \multirow[t]{6}{*}{ 土壤水 } & 2016-07 & 1.85 & 0.29 & 3.60 & 0.20 & 12.2 & & ND & 9.46 & D & ND & .4 & 77 & 05 & 133 \\
\hline & $2016-08-01$ & 4.55 & 0.65 & 3.74 & 0.19 & 12.2 & 1.42 & 6.77 & 4.00 & 0.47 & 0.03 & 19.6 & 5.23 & 5.72 & 70.7 \\
\hline & $2016-08-25$ & 5.85 & 0.44 & 4.11 & 0.27 & 18.3 & 2.13 & 10.9 & 10.6 & 0.56 & 0.25 & 20.5 & 4.74 & 5.59 & 71.3 \\
\hline & $2016-09-18$ & 13.7 & 1.36 & 5.69 & 0.19 & 12.2 & 2.13 & 20.4 & 40.2 & 0.64 & 0.03 & 18.5 & 4.85 & 5.63 & 124 \\
\hline & 平均值 & 6.48 & 0.69 & 4.28 & 0.21 & 13.7 & 4.43 & 12.7 & 16.1 & 0.56 & 0.10 & 20.8 & 5.15 & 5.50 & 99.8 \\
\hline & $C V$ 值 & 67.8 & 59.5 & 19.4 & 14.2 & 19.2 & 99.5 & 44.9 & 88.0 & 12.6 & 100 & 10.7 & 7.82 & 4.79 & 29.0 \\
\hline \multirow[t]{6}{*}{ 酒店自来水 } & $2016-07-09$ & 38.1 & 1.30 & 0.33 & 0.44 & 85.4 & 3.55 & 28.2 & 4.20 & 0.15 & 0.01 & 25.3 & 8.52 & 6.22 & 211 \\
\hline & $2016-$ & 42.9 & 1.56 & 0.37 & 0.45 & 97.6 & 3.55 & 38.0 & 4.00 & 0.15 & 0.09 & 17.3 & 9.40 & 7.19 & 223 \\
\hline & $2016-$ & 46.5 & 0.94 & 0.36 & 0.45 & 110 & 3.55 & 35.5 & 5.11 & 0.18 & 0.20 & 19.1 & 9.56 & 7.97 & 241 \\
\hline & $2016-09-18$ & 47.9 & 1.33 & 0.30 & 0.39 & 98.2 & 2.84 & 50.3 & 4.92 & 0.20 & 0.02 & 15.9 & 8.13 & 8.11 & 233 \\
\hline & 平均值 & 43.8 & 1.28 & 0.34 & 0.43 & 97.8 & 3.37 & 38.0 & 4.56 & 0.17 & 0.08 & 19.4 & 8.90 & 7.37 & 227 \\
\hline & $C V$ 值 & 8.66 & 17.4 & 7.48 & 5.66 & 8.83 & 9.12 & 21.0 & 10.2 & 3.1 & 92.9 & 18.5 & 6.70 & 10.2 & 4.94 \\
\hline \multirow[t]{6}{*}{ 化粪池 } & $2016-07-09$ & 32.2 & 1.08 & 2.15 & 3.73 & 97.6 & 8.5 & 11.8 & 12.0 & 0.29 & 0.94 & 18.9 & 3.42 & 7.22 & 219 \\
\hline & $2016-08-01$ & 37.6 & 1.27 & & & & & 15.7 & & & 0.77 & 17.0 & .71 & & 231 \\
\hline & $2016-08-25$ & 41.1 & 0.75 & 3.24 & 5.58 & 110 & & 16.2 & & & 1.08 & 17.0 & 6.40 & 7.92 & 258 \\
\hline & $2016-09-18$ & 42.3 & 0.99 & 3.56 & 5.60 & 104 & 19.9 & 29.5 & 26.5 & & 1.97 & 15.6 & 4.92 & & 251 \\
\hline & 平均值 & 38.3 & 1.02 & 2.84 & 4.86 & 104 & 12.2 & 18.3 & 19.4 & & 1.19 & 17.1 & 5.11 & 7.55 & 240 \\
\hline & $C V$ 值 & 10.2 & 18.1 & 20.3 & 16.1 & 4.16 & 37.0 & 36.5 & 29.3 & 31.0 & 38.9 & 6.85 & 21.7 & 3.64 & 6.48 \\
\hline \multirow[t]{6}{*}{ 1" 落水洞 } & $2016-07-09$ & 39.6 & 1.70 & 2.96 & 7.18 & 140 & 14.2 & 27.3 & 0.49 & 7.62 & 0.82 & 14.9 & 3.28 & 7.17 & 328 \\
\hline & $2016-08-01$ & 43.3 & 2.28 & 6.37 & 19.5 & 220 & 31.9 & 20.4 & 2.11 & 22.0 & 4.46 & 16.1 & 2.61 & 7.32 & 483 \\
\hline & $2016-08-25$ & 51.5 & 1.55 & 7.16 & 22.7 & 207 & 5.67 & 35.6 & 4.17 & 22.1 & 6.09 & 19.5 & 1.88 & 7.13 & 507 \\
\hline & $2016-09-18$ & 47.3 & 1.81 & 6.74 & 21.6 & 177 & 18.4 & 44.1 & 1.18 & 12.3 & 0.70 & 15.0 & 3.08 & 7.30 & 412 \\
\hline & 平均值 & 45.4 & 1.83 & 5.81 & 17.7 & 186 & 17.5 & 31.9 & 1.99 & 16.0 & 3.02 & 16.4 & 2.71 & 7.23 & 433 \\
\hline & $C V$ 值 & 9.83 & 14.9 & 28.7 & 35.0 & 16.5 & 54.0 & 27.9 & 69.8 & 39.2 & 77.2 & 11.4 & 19.9 & 1.11 & 16.1 \\
\hline
\end{tabular}

* 电导率单位 $\mu \mathrm{S} / \mathrm{cm}$, 水温单位 ${ }^{\circ} \mathrm{C}, \mathrm{pH}$ 值无单位, 其他单位均为 $\mathrm{mg} / \mathrm{L} ; C V$ 值为变异系数, 表示各指标相对于平均值的离 散程度, 单位为 $\%$; MDL 表示低于仪器检测限, ND 表示因样品量不足, 未检测.

\section{表 2 水房泉水文地球化学指标浓度值统计 *}

Tab.2 Value of hydrogeochemical indicators in Shuifang Spring

\begin{tabular}{lccccccccccccccc}
\hline & $\mathrm{Ca}^{2+}$ & $\mathrm{Mg}^{2+}$ & $\mathrm{K}^{+}$ & $\mathrm{Na}^{+}$ & $\mathrm{HCO}_{3}^{-}$ & $\mathrm{Cl}^{-}$ & $\mathrm{SO}_{4}^{2-}$ & $\mathrm{NO}_{3}^{-}$ & $\mathrm{NH}_{4}^{+}$ & $\mathrm{PO}_{4}^{3-}$ & 水温 溶解氧 $\mathrm{pH}$ 值 电导率 \\
\hline 非旅游高峰期(2016-06) & 42.2 & 1.62 & 0.47 & 1.86 & 122.0 & 13.20 & 6.85 & 7.40 & 0.09 & 0.06 & 10.1 & 8.66 & 7.80 & 221.0 \\
旅游高峰期(2016-07-08) & 45.3 & 1.72 & 0.76 & 2.57 & 141.0 & 6.99 & 7.19 & 8.21 & 0.66 & 0.19 & 10.2 & 8.64 & 7.62 & 253.0 \\
旅游高峰期 $C V$ 值 & 9.01 & 13.2 & 43.2 & 35.2 & 10.3 & 33.4 & 43.7 & 13.7 & 95.8 & 71.3 & 0.64 & 4.44 & 0.85 & 11.7 \\
\hline
\end{tabular}

* 电导率单位 $\mu \mathrm{S} / \mathrm{cm}$, 水温单位 ${ }^{\circ} \mathrm{C}, \mathrm{pH}$ 值无单位, 其他单位均为 $\mathrm{mg} / \mathrm{L} ; C V$ 值为变异系数, 表示各指标相对于平均值的离 散程度,单位为 $\%$; 非旅游高峰期、旅游高峰期的样本数 $n$ 分别为 $30 、 76$.

旅游高峰前期(2016 年 7 月 1 日-7 月 21 日): 该阶段某酒店住宿累积量仅 441 人. 水房泉水化学特征 主要受雨水稀释作用影响, 水温、 $\mathrm{pH}$ 值、电导率及 $\mathrm{Ca}^{2+} 、 \mathrm{Mg}^{2+} 、 \mathrm{HCO}_{3}^{-}$浓度显著降低, 流量、浊度在雨量最大阶 段同时出现峰值(图 4). 7 月 1 日, 水房泉各水化学指标均处于低浓度状态, 且未受到降雨等影响, 可代表其 


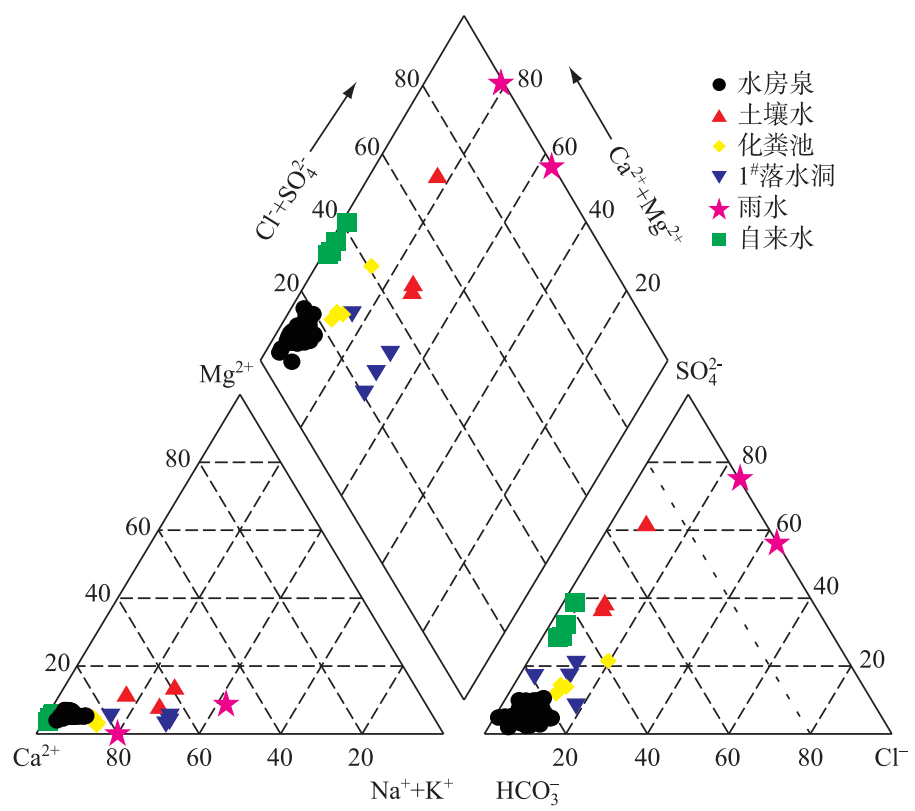

图 3 水房泉流域内各采样点 Piper 图

Fig.3 Piper diagram of sampling sites within the Shuifang Spring Basin

天然背景值.

旅游高峰期间 (2016 年 7 月 22 日- 8 月 27 日) : 重庆整体为伏旱天气, 研究区迎来游客避暑的高峰阶 段,游客累积住宿量突增至 2020 人,水房泉电导率及主要阴、阳离子浓度迅速升高,并于 8 月 25 日前后出现 最高值 (除 $\mathrm{Ca}^{2+} 、 \mathrm{Mg}^{2+} 、 \mathrm{HCO}_{3}^{-}$外; 图 4), 水体发黑、发臭现象明显, 地下水质急剧恶化. 此外, 水房泉各指标的 浓度高峰对周末游客住宿高峰的响应具有一定滞后性, 除了受降雨影响的阶段, 其滞后时间约为 $4 \mathrm{~d}$ (图 4), 与已有的研究认为酒店污水到达水房泉的平均时 间为 $90.3 \mathrm{~h}$ 这一结果基本一致 ${ }^{[19]}$.

旅游高峰后期 $(2016$ 年 8 月 28 日至 9 月 17 日 ) : 伏旱天气基本结束, 山顶气温骤降,住宿游客 累积量锐减至 230 人,加上降雨的稀释作用,主要 离子浓度急剧降低 (图 4), 水房泉水质明显好转.

\section{3 硝酸盐氮氧同位素分布特征}

表 3 为研究区采样点的 $\delta^{15} \mathrm{~N}_{\mathrm{NO}_{3}}$ 和 $\delta^{18} \mathrm{O}_{\mathrm{NO}}$ 值, 其 中酒店自来水中的 $\delta^{15} \mathrm{~N}_{\mathrm{NO}_{3}}$ 和 $\delta^{18} \mathrm{O}_{\mathrm{NO}_{3}}$ 值分别为 $3.7 \% 0 \sim 5.8 \% 0$ 和 $1.6 \%$ 2.7\%o, $1^{\#}$ 落水洞污水的 $\delta^{15} \mathrm{~N}_{\mathrm{NO}_{3}}$ 和 $\delta{ }^{18} \mathrm{O}_{\mathrm{NO}}$ 值分别为 $14.4 \% 0 \sim 21.1 \% 0$ 和 $3.5 \%$ $11.2 \%$, 水房泉的 $\delta^{15} \mathrm{~N}_{\mathrm{NO}_{3}}$ 和 $\delta^{18} \mathrm{O}_{\mathrm{NO}_{3}}$ 值分别为 $5.3 \%$ $17 \%$ 和 $-3.1 \sim 7.3 \%$. 与自来水和水房泉地下水相 比, $1^{\#}$ 落水洞污水的 $\delta^{15} \mathrm{~N}_{\mathrm{NO}_{3}} 、 \delta^{18} \mathrm{O}_{\mathrm{NO}_{3}}$ 明显较为富集.

\section{4 讨论}

\section{1 水房泉水化学变化的影响因素}

岩溶地下水水化学特征常受到不同化学反应

表 3 研究区采样点 $\delta^{15} \mathrm{~N}_{\mathrm{NO}_{3}}$ 和 $\delta^{18} \mathrm{O}_{\mathrm{NO}_{3}}$ 值

Tab.3 Results of nitrogen and oxygen isotopes of the water samples

\begin{tabular}{|c|c|c|c|c|c|}
\hline 采样日期 & 采样点 & $\begin{array}{c}\delta^{15} \mathrm{~N}_{\mathrm{NO}_{3}} / \\
\% 0\end{array}$ & $\begin{array}{l}\text { 标准 } \\
\text { 偏差 }\end{array}$ & $\begin{array}{c}\delta^{18} \mathrm{O}_{\mathrm{NO}_{3}} / \\
\% 0\end{array}$ & $\begin{array}{l}\text { 标准 } \\
\text { 偏差 }\end{array}$ \\
\hline \multirow[t]{2}{*}{$2017-04-29$} & 水房泉 & 17.0 & 0.37 & 3.8 & 0.20 \\
\hline & $1^{\#}$ 落水洞 & 21.1 & 0.37 & 11.2 & 0.20 \\
\hline \multirow[t]{2}{*}{$2017-05-25$} & 水房泉 & 8.4 & 0.37 & 7.3 & 0.20 \\
\hline & 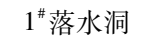 & 14.4 & 0.37 & 3.5 & 0.21 \\
\hline \multirow[t]{2}{*}{$2017-06-19$} & 水房泉 & 7.3 & 0.37 & 3.4 & 0.21 \\
\hline & 酒店自来水 & 4.1 & 0.37 & 2.1 & 0.21 \\
\hline \multirow[t]{2}{*}{$2017-07-12$} & 水房泉 & 7.6 & 0.37 & 2.6 & 0.21 \\
\hline & 酒店自来水 & 5.8 & 0.37 & 2.4 & 0.21 \\
\hline \multirow[t]{2}{*}{$2017-08-7$} & 水房泉 & 5.3 & 0.37 & -3.1 & 0.21 \\
\hline & 酒店自来水 & 3.8 & 0.37 & 2.7 & 0.21 \\
\hline \multirow[t]{2}{*}{$2017-08-28$} & 水房泉 & 10.3 & 0.37 & 2.7 & 0.21 \\
\hline & 酒店自来水 & 3.7 & 0.37 & 2 & 0.21 \\
\hline \multirow[t]{2}{*}{$2017-10-20$} & 水房泉 & 7.1 & 0.37 & 1.6 & 0.21 \\
\hline & 酒店自来水 & 3.7 & 0.37 & 1.6 & 0.21 \\
\hline
\end{tabular}



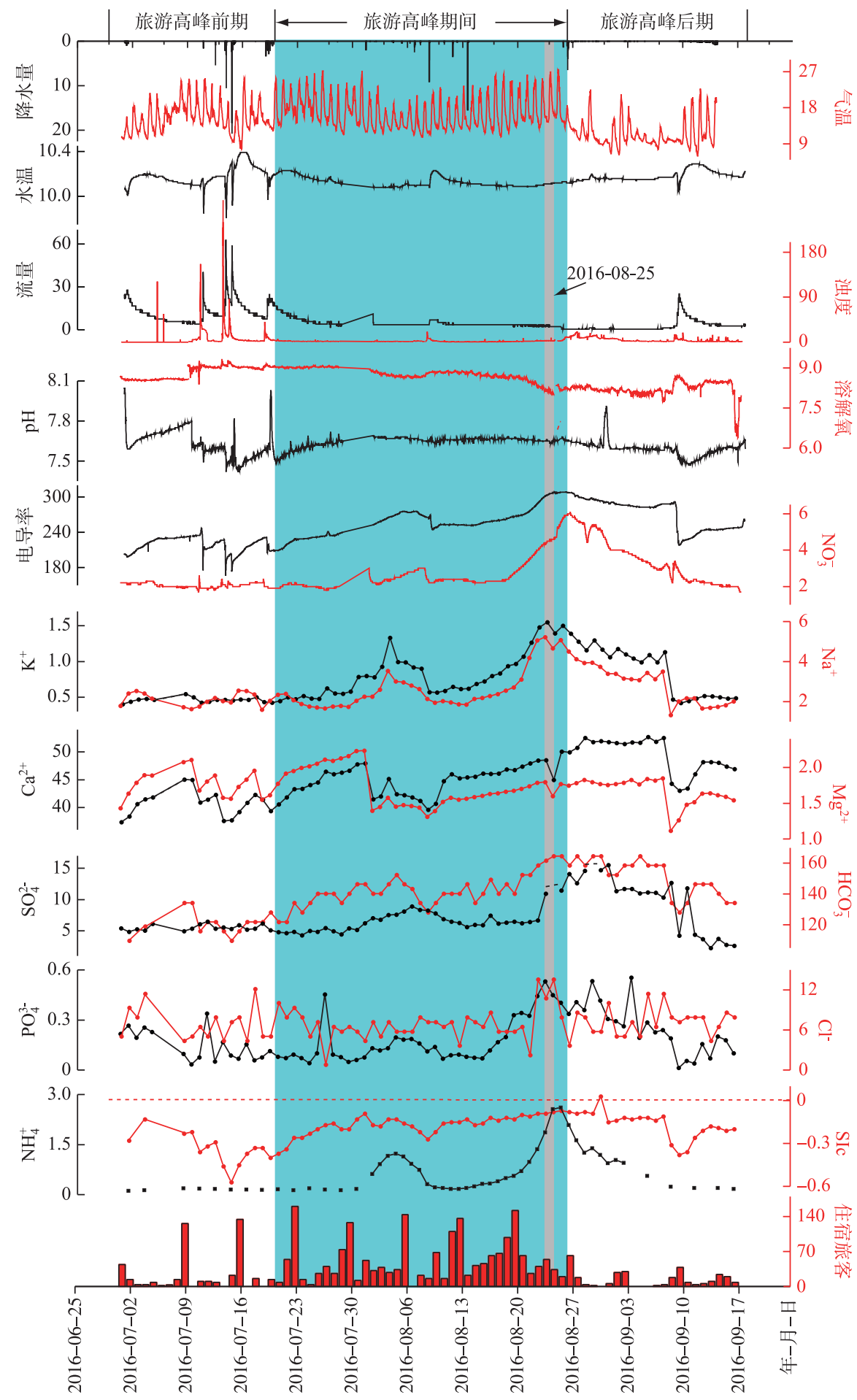

图 42016 年 7 月 1 日至 9 月 17 日水房泉水化学指标变化趋势 (降水量 $/ \mathrm{mm}$, 气温、水温 $/{ }^{\circ} \mathrm{C}$, 流量 $/(\mathrm{L} / \mathrm{s})$, 浊度/NTU, 电导率/ $(\mu \mathrm{S} / \mathrm{cm}), \mathrm{pH}$ 值、SIc 无单位, 住宿旅客/人,其他指标单位 $/(\mathrm{mg} / \mathrm{L})$

Fig.4 Variation trend of hydrochemical indicators of Shuifang Spring, July 1st to September 17th, 2016 
过程、自然条件、人为活动的影响 ${ }^{[25,27]}$. Gibbs 图可以清楚地反映天然水体中各种离子的起源机制及演化趋 势, 图中中间部位、右上角、右下角分别表示水化学特征受到水岩作用、蒸发结晶作用、降雨的控制 ${ }^{[28]}$. 随着 人为活动对各地表、地下水体影响的深人, Gibbs 图的局限性也逐渐显现. 由于重庆市位于内陆季风区, 不存 在卤化矿物地层 ${ }^{[29]}$, 加上研究区仅存在旅游活动, 没有农业、工业活动的影响, 因此可将图中右上角的蒸发 结晶作用改进为旅游酒店排污的影响 (图 5). 由图 5 可知, 水房泉、自来水、化粪池等采样点的样品均落在 水岩作用控制的范围内; 土壤水化学特征受水岩作用、降雨作用的共同控制; $1^{\#}$ 落水洞污水主要受旅游酒店 排污的影响.
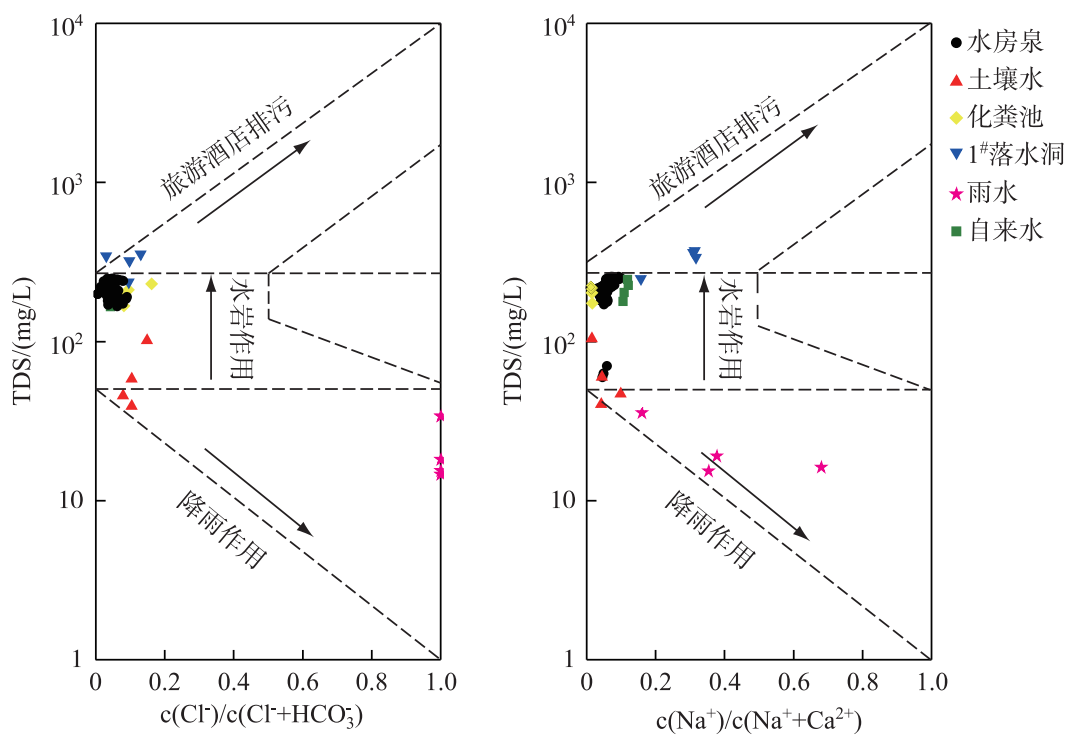

图 5 水房泉流域内各采样点 Gibbs 图

Fig.5 Gibbs plots of the sampling sites in Shuifang Spring basin

地下水中 $\mathrm{K}^{+} 、 \mathrm{Na}^{+}$的主要来源为含钠岩石 ${ }^{[3]}$ 及岩盐矿化物 ${ }^{[30-31]}$ 的溶解、离子置换、化肥施用、大气降水、 生活废水等 ${ }^{[6]} ; \mathrm{NO}_{3}^{-} 、 \mathrm{Cl}^{-} 、 \mathrm{NH}_{4}^{+} 、 \mathrm{PO}_{4}^{3-}$ 主要来源于农肥、生产生活废水排放、垃圾滤液渗漏、化粪池和排污管道 泄露、人畜排泄物等人为输人 ${ }^{[30,32-33]}$; 自然状态下的 $\mathrm{Cl}^{-}$主要来自大气输人; $\mathrm{SO}_{4}^{2-}$ 除了来自蒸发盐岩溶解和硫 化物氧化外, 酸雨沉降和工业废水输人对其也有一定影响 ${ }^{[25]}$. 水房泉样品中 $\mathrm{K}^{+} 、 \mathrm{Na}^{+} 、 \mathrm{NO}_{3}^{-} 、 \mathrm{Cl}^{-} 、 \mathrm{NH}_{4}^{+} 、 \mathrm{PO}_{4}^{3-}$ 、 $\mathrm{SO}_{4}^{2-}$ 的检出率均为 $100 \%$, 为进一步探究其各离子来源, 改变 Gibbs 图横轴的阴、阳离子当量浓度比例式 $\mathrm{c}\left(\mathrm{Cl}^{-}\right) / \mathrm{c}\left(\mathrm{Cl}^{-}+\mathrm{HCO}_{3}^{-}\right)$和 $\mathrm{c}\left(\mathrm{Na}^{+}\right) / \mathrm{c}\left(\mathrm{Na}^{+}+\mathrm{Ca}^{2+}\right)$, 将 $\mathrm{NO}_{3}^{-} 、 \mathrm{PO}_{4}^{3-} 、 \mathrm{SO}_{4}^{2-}$ 和 $\mathrm{K}^{+} 、 \mathrm{NH}_{4}^{+}$等带有人类活动影响特征的 离子当量浓度分别代人上述比例式后得到图 6.

与图 5 相比, 自来水、化粪池污水、土壤水水化学特征的影响因素无明显变化, 但各样品往图中右侧出 现了偏移; $1^{\#}$ 落水洞污水则转变为完全受旅游酒店排污的控制; 水房泉水化学变化仍主要受控于水岩作用, 但其全部样品往右侧偏移明显 (图 6), 说明加人上述带有人类活动影响特征的离子后, 地下水受到水岩作用 的影响更为强烈. 由于水房泉与化粪池、 $1^{\#}$ 落水洞污水存在紧密的水力联系, 可见酒店排污的影响逐渐参与 到其水化学的演变过程中. 水房泉较高浓度的 $\mathrm{K}^{+} 、 \mathrm{Na}^{+} 、 \mathrm{Cl}^{-} 、 \mathrm{NH}_{4}^{+} 、 \mathrm{NO}_{3}^{-} 、 \mathrm{PO}_{4}^{3-}$ 主要来自酒店、㕌房生活污水及 剩菜残汁、人类粪便等的排放; 区域煤层中黄铁矿的氧化 ${ }^{[24]}$ 、酸雨对 $\mathrm{SO}_{4}^{2-}$ 浓度的贡献较大.

\section{2 基于氮氧同位素的硝酸盐来源}

为了进一步验证该旅游酒店排污对水房泉水质的影响, 根据表 3 绘制成 $\delta^{15} \mathrm{~N}_{\mathrm{NO}_{3}}$ 与 $\delta^{18} \mathrm{O}_{\mathrm{NO}_{3}}$ 的关系图 (图 7), 示踪酒店污废水对水房泉中硝酸盐的影响. 可见, 酒店自来水中的 $\delta^{15} \mathrm{~N}_{\mathrm{NO}_{3} 、} \delta^{18} \mathrm{O}_{\mathrm{NO}}$ 值落在大气沉降和肥 料中 $\mathrm{NH}_{4}^{+}$以及土壤有机氮混合贡献范围值内 ${ }^{[34]}$. 然而, 研究区内禁止农业种植活动, 因此可以排除肥料对 

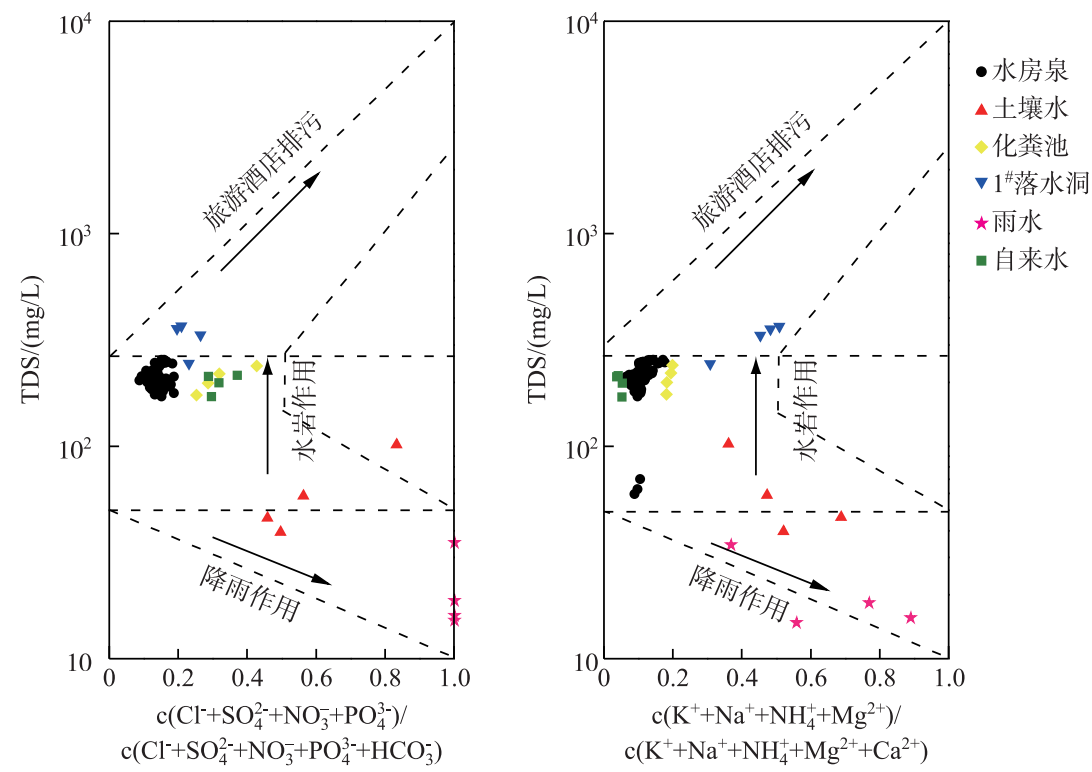

图 6 变化后的 Gibbs 图

Fig.6 Gibbs plots after change

酒店自来水 $\mathrm{NO}_{3}^{-}$的贡献, 因此自来水中的 $\mathrm{NO}_{3}^{-}$主要来源于大气降水和土壤有机氮, 故从 $\delta^{15} \mathrm{~N}_{\mathrm{NO}}$ 和 $\delta^{18} \mathrm{O}_{\mathrm{NO}_{3}}$ 来 看, 酒店自来水处于自然本底值. $1^{\#}$ 落水洞污水的 $\delta^{15} \mathrm{~N}_{\mathrm{No}}$ 和 $\delta^{18} \mathrm{O}_{\mathrm{No}}$ 值较高, 落在粪便和污水贡献的范围值 内 $^{[34]}$, 进一步验证了其水质深受酒店污废水排放的影响. 2017 年 4 月 29 日、8 月 28 日水房泉的 $\delta^{15} \mathrm{~N}_{\mathrm{NO}}$ 和 $\delta^{18} \mathrm{O}_{\mathrm{No}}$ 值样品落在粪便和污水贡献的范围值内, 其余数据落在污水以及土壤有机氮的混合端元 ${ }^{[34]}$. 若水房 泉地下水未受某酒店污废水的影响, 则它与该酒店自来水的 $\delta^{15} \mathrm{~N}_{\mathrm{NO}} 、 \delta^{18} \mathrm{O}_{\mathrm{No}}$ 值应与酒店自来水一致落在大 气降水和土壤有机氮的贡献范围内, 但水房泉 $\delta{ }^{15} \mathrm{~N}_{\mathrm{NO}_{3}} 、 \delta^{18} \mathrm{O}_{\mathrm{No}}$ 值的分布并非如此, 其明显受到了粪便和污废

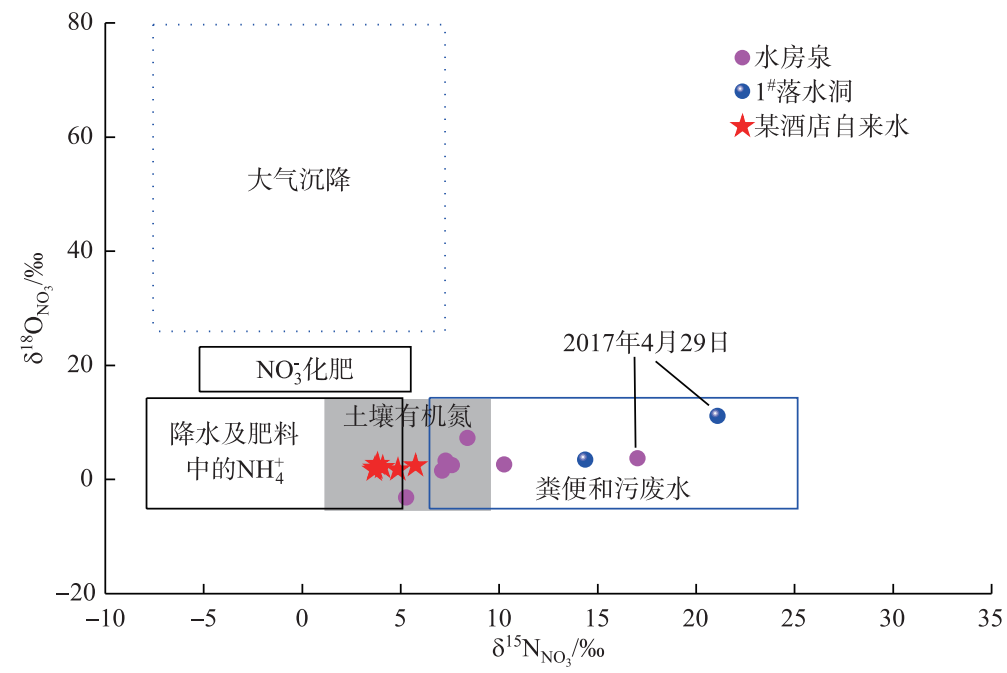

图 7 研究区 $\delta^{15} \mathrm{~N}_{\mathrm{NO}_{3}}$ 与 $\delta^{18} \mathrm{O}_{\mathrm{NO}_{3}}$ 的关系(不同 $\mathrm{N}$ 来源对应的同位素值引自文献[34])

Fig.7 Schematic for source identification based on $\delta^{15} \mathrm{~N}_{\mathrm{NO}_{3}}$ and $\delta^{18} \mathrm{O}_{\mathrm{NO}_{3}}$ values 
水的影响 (图 7). 需要指出的是, 因 4 月 29 日恰逢五一黄金周前夕的周末,也是杜鹃花观赏的高峰时段, 8 月 28 日处于金佛山的避暑高峰期,剧增的酒店污废水排放对地下水 $\mathrm{NO}_{3}^{-}$影响尤为明显.

\section{3 水房泉水化学变化原因探析}

4.3.1 与水岩作用相关的离子变化原因 $\mathrm{Ca}^{2+} 、 \mathrm{Mg}^{2+} 、 \mathrm{HCO}_{3}^{-}$是岩溶区碳酸盐岩溶蚀的产物, 这种溶蚀过程可 描述为:

$$
\mathrm{Ca}_{\mathrm{x}} \mathrm{Mg}_{(1-\mathrm{x})} \mathrm{CO}_{3}+\mathrm{H}_{2} \mathrm{CO}_{3}=\mathrm{xCa}^{2+}+(1-\mathrm{x}) \mathrm{Mg}^{2+}+2 \mathrm{HCO}_{3}^{-}
$$

监测期间, $\mathrm{Ca}^{2+} 、 \mathrm{Mg}^{2+} 、 \mathrm{HCO}_{3}^{-}$浓度的变化主要受控于水岩作用,降雨期间受到稀释作用的影响, 其浓度均 表现出相应的降低趋势 (图 4). 旅游高峰前期, $\mathrm{Ca}^{2+} 、 \mathrm{Mg}^{2+} 、 \mathrm{HCO}_{3}^{-}$浓度变化平稳; 旅游高峰期间, 其浓度整体 增加; 旅游高峰后期, 上述离子浓度并未随其他离子呈现急剧降低的趋势, 反而滞后于其他离子出现最高浓 度(图 4), 具有较高的浓度增幅(表 4)。

表 4 水房泉各指标浓度极值变化百分比 $/ \%$ *

Tab.4 Percentage variation of the extreme concentrations of Shuifang Spring indicators

\begin{tabular}{|c|c|c|c|c|c|c|c|c|c|c|c|c|}
\hline \multirow{2}{*}{ 指标 } & \multicolumn{8}{|c|}{ 旅游高峰期间 } & \multicolumn{4}{|c|}{ 旅游高峰后期 } \\
\hline & $\mathrm{K}^{+}$ & $\mathrm{Na}^{+}$ & $\mathrm{Cl}^{-}$ & $\mathrm{NO}_{3}^{-}$ & $\mathrm{NH}_{4}^{+}$ & $\mathrm{PO}_{4}^{3-}$ & 电导率 & 溶解氧 & $\mathrm{Ca}^{2+}$ & $\mathrm{Mg}^{2+}$ & $\mathrm{HCO}_{3}^{-}$ & $\mathrm{SO}_{4}^{2-}$ \\
\hline 背景值 & 0.40 & 1.80 & 5.07 & 8.02 & 1.27 & 0.22 & 199 & 8.58 & 37.40 & 1.43 & 110.00 & 5.39 \\
\hline 极值 & 1.55 & 5.23 & 13.60 & 11.00 & 2.56 & 0.53 & 308 & 8.19 & 52.7 & 1.84 & 165.00 & 15.50 \\
\hline 变化百分比 & 284.00 & 190.00 & 168.00 & 37.00 & 102.00 & 145.00 & 55 & -5.00 & 41.00 & 28.50 & 50.00 & 187.00 \\
\hline
\end{tabular}

* 背景值取自 2016 年 7 月 1 日 $\left(7\right.$ 月 1 日 $\mathrm{HCO}_{3}^{-} 、 \mathrm{NH}_{4}^{+}$数据缺失, 故就近取 7 月 2 日数据), 变化百分比 $=($ 极值 - 背景值 $) /$ 背景值,正、负值分别为指标增长、降低百分比.

当自然状态下只有 $\mathrm{H}_{2} \mathrm{CO}_{3}$ 参与岩溶作用时, $\left(\mathrm{Ca}^{2+}+\mathrm{Mg}^{2+}\right) / \mathrm{HCO}_{3}^{-}$摩尔比值为 0.5 , 若有其他酸类物质参与 其中, $\left(\mathrm{Ca}^{2+}+\mathrm{Mg}^{2+}\right) / \mathrm{HCO}_{3}^{-}$的理论摩尔比应为 $1^{[27]}$. 监测期间水房泉的 $\left(\mathrm{Ca}^{2+}+\mathrm{Mg}^{2+}\right) / \mathrm{HCO}_{3}^{-}$摩尔比均值为 0.53 , 最大值 0.58 , 且地下水 SIc 基本 $<0$ (图 4), 处于溶蚀状态, 说明有其他酸类物质参与了碳酸盐岩的溶 蚀, 造成了水房泉 $\mathrm{Ca}^{2+} 、 \mathrm{Mg}^{2+} 、 \mathrm{HCO}_{3}^{-}$浓度的显著增加. 其中, $\mathrm{H}_{2} \mathrm{SO}_{4}$ 对碳酸盐岩的溶蚀过程可以表示为:

$$
2 \mathrm{Ca}_{\mathrm{x}} \mathrm{Mg}_{(1-\mathrm{x})} \mathrm{CO}_{3}+\mathrm{H}_{2} \mathrm{SO}_{4}=2 \mathrm{xCa}^{2+}+2(1-\mathrm{x}) \mathrm{Mg}^{2+}+\mathrm{SO}_{4}^{2-}+2 \mathrm{HCO}_{3}^{-}
$$

由式 (2) 可知, $\mathrm{H}_{2} \mathrm{SO}_{4}$ 的溶蚀会导致地下水中 $\mathrm{SO}_{4}^{2-}$ 与 $\mathrm{Ca}^{2+} 、 \mathrm{Mg}^{2+} 、 \mathrm{HCO}_{3}^{-}$浓度的共同增加, 这与旅游高峰后 期 $\mathrm{SO}_{4}^{2-}$ 与 $\mathrm{Ca}^{2+} 、 \mathrm{Mg}^{2+} 、 \mathrm{HCO}_{3}^{-}$相似的浓度变化趋势是一致的 (图 4).

除 $\mathrm{H}_{2} \mathrm{SO}_{4}$ 外,生活污废水中含有的 $\mathrm{HNO}_{3} 、 \mathrm{HCl}$ 及有机质代谢分解产生的有机酸等也可能参与了碳酸盐 岩的溶蚀 ${ }^{[35-37]}$, 且其影响具有持续性, 长此以往可能会加速岩溶含水介质的演化速度.

4.3.2 与酒店污水排放相关的离子变化原因 地下水溶质运移过程包括机械弥散和分子扩散过程,是研究地 下水污染物质扩散及污染预测的理论依据 ${ }^{[38]}$. 岩溶地下水中污染物的扩散受到岩溶含水介质长度、内部结 构、地下水流速等因素影响 ${ }^{[39]}$. 水房泉流域岩溶地下管道发育良好, 内无较大溶潭发育, 地下水流速快, 这 为污染成分在管道中的快速运移、扩散提供了条件, 故水房泉的水化学变化迅速, 主要离子浓度高峰对污废 水排放事件的响应仅滞后约 $4 \mathrm{~d}$ (图 4).

人体排泄物中富含 $\mathrm{K} 、 \mathrm{Na}$ 、含氮有机质, 酒店及欴房生活污水中富含 $\mathrm{NaClO} 、 \mathrm{C}_{17} \mathrm{H}_{35} \mathrm{COONa}$ (硬脂酸钠) 、 $\mathrm{C}_{18} \mathrm{H}_{30} \mathrm{O}_{3} \mathrm{~S}$ (十二苯磺酸)、 $\mathrm{Na}_{4} \mathrm{P}_{2} \mathrm{O}_{7}$ (磷酸四钠盐) 等, 以上成分溶人水体后主要表现为 $\mathrm{K}^{+} 、 \mathrm{Na}^{+} 、 \mathrm{NH}_{4}^{+} 、 \mathrm{Cl}^{-} 、$ $\mathrm{PO}_{4}^{3-}$ 等 ${ }^{[40]}$. 在旅游高峰时段, 大量化学成分复杂的生活污废水未能经过化粪池的充分沉降和处理便通过 $1^{\#}$ 落水洞排人岩溶含水层中, 使地下水中的各离子浓度变化显著. 将 2016 年 8 月 25 日水房泉的主要水化学指 标与自来水 (视为区域本底值) 进行对比, 可见水房泉中电导率及 $\mathrm{K}^{+} 、 \mathrm{Na}^{+} 、 \mathrm{Cl}^{-} 、 \mathrm{NO}_{3}^{-} 、 \mathrm{NH}_{4}^{+} 、 \mathrm{PO}_{4}^{3-}$ 等浓度增加 显著(表 5).

污水中有机质的存在 ( $1^{\#}$ 落水洞污水中的 TOC 浓度 $>50 \mathrm{mg} / \mathrm{L}$, 数据未发表) 也影响到 $\mathrm{SO}_{4}^{2-}$ 浓度, $\mathrm{SO}_{4}^{2-}$ 在 细菌的作用下会生成 $\mathrm{H}_{2} \mathrm{~S}$, 使水体发臭, $\mathrm{SO}_{4}^{2-}$ 浓度相应降低, 其化学反应过程如式 (3) 所示:

$$
2 \mathrm{CH}_{2} \mathrm{O}+\mathrm{SO}_{4}^{2-}=\mathrm{H}_{2} \mathrm{~S}_{(\mathrm{g})}+2 \mathrm{HCO}_{3}^{-}
$$


表 52016 年 8 月 25 日水房泉较自来水指标变化百分比”

Tab.5 Percentage variation of indicators in Shuifang Spring compared with tap water on August $25^{\text {th }}, 2016$

\begin{tabular}{|c|c|c|c|c|c|c|c|c|c|c|c|c|}
\hline 指标 & $\mathrm{K}^{+}$ & $\mathrm{Na}^{+}$ & $\mathrm{Cl}^{-}$ & $\mathrm{NO}_{3}^{-}$ & $\mathrm{NH}_{4}^{+}$ & $\mathrm{PO}_{4}^{3-}$ & 电导率 & 溶解氧 & $\mathrm{Ca}^{2+}$ & $\mathrm{Mg}^{2+}$ & $\mathrm{HCO}_{3}^{-}$ & $\mathrm{SO}_{4}^{2-}$ \\
\hline 变化百分比/\% & 330 & 1019 & 260 & 167 & 1322 & 155 & 24.1 & -8.1 & 4.7 & 33.3 & 50 & -82.7 \\
\hline
\end{tabular}

* 正值为指标增长百分比,负值为指标降低百分比.

2016 年 8 月 25 日 $1^{\#}$ 落水洞污水水体发臭现象明显, 可见有机质参与了上述反应, 消耗了污废水中的 $\mathrm{SO}_{4}^{2-}$, 削弱了其对水房泉 $\mathrm{SO}_{4}^{2-}$ 浓度的贡献.

此外, 在酒店厨房生活污水的直接排放作用下, 虽然水房泉 $\mathrm{K}^{+} 、 \mathrm{Na}^{+} 、 \mathrm{NH}_{4}^{+} 、 \mathrm{PO}_{4}^{3-}$ 等离子浓度于旅游高峰 期显著升高, 但其水化学类型总体仍表现为 $\mathrm{HCO}_{3}-\mathrm{Ca}$ 型, 大部分指标仍符合我国地下水质量标准 ( $\mathrm{GB}$ 14848-2017) 中的 I 类水质要求. 尽管如此, 主要离子浓度在旅游高峰期升高的现象却不容忽视.

\section{5 结论与不足}

1) 旅游高峰期金佛山水房泉主要离子浓度整体升高明显, 并且其水化学变化与酒店游客住宿量密切相 关, 总体表现为三阶段: 旅游高峰前期, 住宿量较少, 各指标受降雨影响显著; 旅游高峰期间, 住宿量的突增 使水房泉水质急剧恶化; 旅游高峰后期, 住宿量锐减使水质明显好转.

2) 受到研究区内某酒店污废水的补给, 其 $\mathrm{K}^{+} 、 \mathrm{Na}^{+} 、 \mathrm{Cl}^{-} 、 \mathrm{NH}_{4}^{+} 、 \mathrm{PO}_{4}^{3-}$ 等离子浓度显著升高, $\delta^{15} \mathrm{~N}_{\mathrm{NO}_{3}} 、 \delta^{18} \mathrm{O}_{\mathrm{NO}_{3}}$ 证明水房泉受到某酒店排放污废水的影响, 旅游餐饮、住宿等酒店排污活动参与到其水化学的演变过程中.

3) $\mathrm{H}_{2} \mathrm{SO}_{4}$ 及酒店污废水中 $\mathrm{HNO}_{3} 、 \mathrm{HCl}$ 、有机酸等可能参与了碳酸盐岩的溶蚀, 使水房泉 $\mathrm{Ca}^{2+} 、 \mathrm{Mg}^{2+} 、 \mathrm{HCO}_{3}^{-}$ 浓度增加明显; 酒店污废水在流域岩溶管道内的快速扩散, 使水房泉水化学变化迅速, 主要离子浓度高峰对 污废水排放事件的响应仅滞后约 $4 \mathrm{~d}$; 长期排污可能会对岩溶含水介质演化产生影响. 因此, 建议相关管理 部门高度重视排污对金佛山世界自然遗产地岩溶地下水系统的影响.

然而无法收集到研究期间在某酒店用餐的游客数量, 加上我们对研究区各水体 $\delta^{15} \mathrm{~N}_{\mathrm{NO}_{3}} 、 \delta^{18} \mathrm{O}_{\mathrm{NO}_{3}}$ 的研究 工作始于 2017 年 4 月,滞后于各水体水化学指标的监测研究,这两点甚为遗憾.

致谢: 感谢张宇、盛婷、谢国文、覃殁、张海月等硕士研究生在野外和实验工作中的帮助.

\section{6 参考文献}

[ 1 ] Ford D, Williams PW eds. Karst hydrogeology and geomorphology. Wiley, 2007.

[ 2 ] Yuan DX ed. Chinese Karst Science. Beijing: Geological Publishing House, 1993: 149-150. [袁道先. 中国岩溶学. 北 京: 地质出版社, 1993: 149-150.]

[ 3 ] Helena B, Pardo R, Vega M et al. Temporal evolution of groundwater composition in an alluvial aquifer (Pisuerga River, Spain) by principal component analysis. Water Research, 2000, 34(3) : 807-816.

[ 4 ] Chan HJ. Effect of land use and urbanization on hydrochemistry and contamination of groundwater from Taejon area, Korea. Journal of Hydrology, 2001, 253(1/2/3/4) : 194-210.

[ 5 ] Jiang YJ, Zhang C, Yuan DX et al. Impact of land use change on groundwater quality in a typical karst watershed of southwest China: a case study of the Xiaojiang watershed, Yunnan Province. Hydrogeology Journal, 2008, 16(4) : 727-735.

[6] Jiang YJ, Wu YX, Chris Groves et al. Identification of influencing factors of groundwater quality variation using factor analysis. Hydrogeology \& Engineering Geology, 2009, 36(4): 1-7. [蒋勇军, 吴月霞, Chris Groves 等. 利用因子分析 确定岩溶地下河系统水质的影响因素. 水文地质工程地质, 2009, 36(4): 1-7.]

[ 7 ] Evangelista PP. Assessment of agricultural systems and their impact on the quality of groundwater resources in the Philippines. Aciar Proceedings, Australian Centre for International Agricultural Research, 1996: 93-94.

[ 8 ] Yang PH, Yuan DX, Yuan WH et al. Formations of groundwater hydrogeochemistry in a karst system during storm events as revealed by PCA. Chinese Science Bulletin, 2010, 55(14): 1412-1422.

[ 9 ] Barnes RT, Raymond PA. The contribution of agricultural and urban activities to inorganic carbon fluxes within temperate watersheds. Chemical Geology, 2009, 266(3/4) : 318-327. 
[10] Zhan ZJ, Chen F, Yang PH et al. Comparison on the hydrogeochemical characteristics of typical karst groundwater system in southwest China, a case of Qingmuguan and Laolongdong in Chongqing. Environmental Science, 2016, 37(9) : 3365 3374. [詹兆君, 陈峰, 杨平恒等. 西南典型岩溶地下河系统水文地球化学特征对比: 以重庆市青木关、老龙洞为 例. 环境科学, 2016, 37(9): 3365-3374.]

[11] Jiang YJ, Yuan DX. Geochemical traces to characterize effects of urbanization on karst groundwater quality from Nanshan underground river system, SW China. Quaternary Sciences, 2014, 34(5): 1044-1053. [蒋勇军, 袁道先. 城市发展对 岩溶地下水质影响的地球化学示踪一以重庆南山老龙洞地下河系统为例. 第四纪研究, 2014, 34(5): 10441053.]

[12] Ren K, Yang PH, Jiang ZL et al. Variation characteristics and sources of heavy metals in an urban karst groundwater system during rainfall event. Environmental Science, 2015, 36(4) : 1270-1276. [任坤, 杨平恒, 江泽利等. 降雨期间岩溶 城镇区地下河水重金属变化特征及来源解析. 环境科学, 2015, 36(4) : 1270-1276.]

[13] Wang J, Bao WK, He BH et al. Effect of tourism on nitrogen and phosphorus loss in surface runoff in Jiuzhaigou world nature heritage reserve. Ecology and Environment, 2006, 15(2):284-288. [王晶, 包维楷, 何丙辉等. 旅游活动对九寨 沟地表径流氮磷流失的影响研究. 生态环境学报, 2006, 15(2): 284-288.]

[14] Wang C, Ying J, Qiu XZ. Effect of tourism activities on sand lake water quality. Ningxia Engineering Technology, 2016, 15(1) : 82-87. [汪超, 尹娟, 邱小琮. 旅游活动对沙湖水环境质量影响评价. 宁夏工程技术, 2016, 15(1): 82-87.]

[15] Kaseva ME, Moirana JL. Problems of solid waste management on Mount Kilimanjaro: a challenge to tourism. Waste Management Research the Journal of the International Solid Wastes \& Public Cleansing Association Iswa, 2010, 28 ( 8 ): 695-704.

[16] Andres-Abellan M, Alamo JB, Landete-Castillejos T et al. Impacts of visitors on soil and vegetation of the recreational area " Nacimiento del Río Mundo" (Castilla-La Mancha, Spain). Environmental Monitoring \& Assessment, 2005, 101(1/3): 55-67.

[17] Zhang JL, Wang HJ, Dong L et al. An analysis of travertine landscape degradation in Huanglong ravine of Sichuan, a world's heritage site, and its causes and protection countermesures. Acta Geoscientica Sinica, 2012, 33(1): 111-120. [张金流, 王海静, 董立等. 世界遗产——四川黄龙钻华景观退化现象、原因及保护对策分析. 地球学报, 2012, 33 (1) : 111-120.]

[18] Li YG. Study on dynamic variation and influencing factors of karst groundwater quality: a case study of Shuifang Spring, Mt. Jinfo, China [Dissertation]. Chongqing: Southwest University, 2009. [李营刚. 岩溶地下水质动态变化和影响因 素研究——重庆金佛山水房泉为例 [学位论文]. 重庆: 西南大学, 2009.]

[19] Yu ZL, Yuan DX, Yang PH et al. Influences of tourism activities on hydrochemistry of karst groundwater revealed by principal analysis and on-line monitoring technique. Acta Geoscientica Sinica, 2016, 37(2) : 232-240. [于正良, 袁道先, 杨 平恒等. 基于 PCA 和在线监测技术研究旅游活动对岩溶地下水水化学的影响. 地球学报, 2016, 37 (2): 232-240.]

[20] Wu YX, Jiang YJ, Yuan DX et al. Simulation of hydrological response of karst spring to precipitation—case study of Shuifang Spring, Jinfo Mt., Chongqing. Hydrogeology \& Engineering Geology, 2007, 6: 41-48. [吴月霞, 蒋勇军, 袁道先 等. 岩溶泉域降雨径流水文过程的模拟一一重庆金佛山水房泉为例. 水文地质工程地质, 2007, 6: 41-48.]

[21] Li LL, Kuang MS, Jiang YJ et al. Study on the karst ecosystem of mountain Jinfo. Journal of Sichuan Normal University: Nature Science, 26(2) : 201-204. [ 李林立, 况明生, 蒋勇军等. 金佛山岩溶生态系统初步探讨一一岩溶泉水化学 特征分析. 四川师范大学学报: 自然科学版, 2003, 26(2) : 201-204.]

[22] The master planning for Jinfoshan National Park in Nanchuan(2016-2030). Chongqing City, Jinfo Mountain Scenic Area Management Bureau Nanchuan District, 2016. [金佛山风景名胜区总体规划(2016-2030). 重庆市南川区金佛山风 景名胜区管理局, 2016.]

[23] Jiang ZC, Luo WQ, Wu HY et al. Collecting instrument of soil water. CN202049071U. 2011-11-23. [蒋忠诚, 罗为群, 吴华英等. 渗流土壤水收集器. 中国, CN202049071U. 2011-11-23.]

[24] Li T. Study on groundwater pollution risk assessment of abandoned coal mine [Dissertation]. Xuzhou: China University of Mining and Technology, 2014. [李庭. 废弃矿井地下水污染风险评价研究 [学位论文]. 徐州: 中国矿业大 学, 2014.] 
[25] Lang YC, Liu CQ, Zhao ZQ et al. Chemical compositions of surface and ground waters of Guiyang city: discussion of water-rock interaction and contamination in karstic hydrological system. Advances in Water Science, 2005, 16(6) : 826-832. [郎雔超, 刘丛强, 赵志琦等. 贵阳市地表水地下水化学组成: 喀斯特水文系统水-岩反应及污染特征. 水科学进 展, 2005, 16(6): 826-832.]

[26] Zhang YZ, He QF, Jiang YJ et al. Characteristics and transport patterns of ammonia, nitrites, nitrates and inorganic nitrogen flux at epikarst springs and a subterranean stream in Nanshan, Chongqing. Environmental Science, 2016, 37 (4): 1379-1388. [张远瞩, 贺秋芳, 蒋勇军等. 重庆南山表层岩溶泉与地下河三氮运移及氮通量估算. 环境科学, 2016, 37(4) : 1379-1388.]

[27] Jiang YJ. The contribution of human activities to dissolved inorganic carbon fluxes in a karst underground river system: evidence from major elements and $\delta^{13} \mathrm{C}(\mathrm{DIC})$ in Nandong, Southwest China. Journal of Contaminant Hydrology, 2013, 152: 1-11.

[28] Gibbs RJ. Mechanisms controlling world water chemistry. Science, 1970, 170(3962) : 1088-1090.

[29] Pu JB, Yuan DX, Jiang YJ et al. Hydrogeochemistry and environmental meaning of Chongqing subterranean karst streams in China. Advances in Water Science, 2010, 21(5): 628-636. [蒲俊兵, 袁道先, 蒋勇军等. 重庆岩溶地下河水文地 球化学特征及环境意义. 水科学进展, 2010, 21(5): 628-636.]

[30] Valdes D, Dupont JP, Laignel B et al. A spatial analysis of structural controls on Karst groundwater geochemistry at a regional scale. Journal of Hydrology, 2007, 340(3/4) : 244-255.

[31] Aiuppa A, Bellomo S, Brusca L et al. Natural and anthropogenic factors affecting groundwater quality of an active volcano (Mt. Etna, Italy). Applied Geochemistry, 2003, 18(6): 863-882.

[32] Savoie \& Amp DL, Prospero JM. Comparison of oceanic and continental sources of non-sea-salt sulphate over the Pacific Ocean. Nature, 1989, 339(6227): 685-687.

[33] Rose S. The effects of urbanization on the hydrochemistry of base flow within the Chattahoochee River Basin (Georgia, USA) . Journal of Hydrology, 2007, 341 (1/2) : 42-54.

[34] Nestler A, Berglund M, Accoe F et al. Isotopes for improved management of nitrate pollution in aqueous resources: review of surface water field studies. Environmental Science \& Pollution Research, 2011, 18(4) : 519-533.

[35] Kogovšek J. Impact of chlorides, nitrates, sulfates and phosphates on increased limestone dissolution in the karst vadose zone (postojna cave, slovenia). Acta Carsologica, 2011, 40(2) : 319-327.

[36] Wang L, Zeng C, Meng H et al. Water geochemistry and dissolution rates of the karst-dominated Houzhai River basin, China. Toxicological \& Environmental Chemistry, 2016, 98(5/6): 648-657.

[37] Hamdan I, Sauter M, Margane A et al. Groundwater vulnerability assessment for the karst aquifer of Tanour and Rasoun spring using EPIK, COP, and travel time methods. EGU General Assembly, 2016.

[38] Xu YL. Experimental study of contaminant transport and the velocity dependence of dispersion in porous media [Dissertation]. Hefei : Hefei University of Technology, 2017. [徐玉璐. 多孔介质中污染物运移及弥散系数对流速依赖性实验 研究 [学位论文]. 合肥: 合肥工业大学, 2017.]

[39] Zhao XE, Chang Y, Peng F et al. Experimental study of solute transporting pool-pipe system and its significance on karst hydrogeology. Journal of Jilin University: Earth Science Edition, 2017, 47(4)：1219-1228. [赵小二, 常勇, 彭伏等. 水 箱-管道系统溶质运移实验研究及其岩溶水文地质意义. 吉林大学学报: 地球科学版, 2017, 47(4) : 1219-1228.]

[40] Ren J, Yang PH, Wang JL et al. Influences of tourism activities on evolution of physicochemical parameters in karst groundwater and its conceptual model: a case study of Jinfoshan Shuifang Spring in the World Natural Heritage Site. Resources and Environment in the Yangtze Basin, 2018, 27(1):97-106. [任娟, 杨平恒, 王建力等. 旅游活动影响下的 岩溶地下水理化特征演化及其概念模型——世界自然遗产地金佛山水房泉为例. 长江流域资源与环境, 2018, 27(1): 97-106.] 